\title{
Benefit-risk assessment of rivaroxaban versus enoxaparin for the prevention of venous thromboembolism after total hip or knee arthroplasty
}

\author{
This article was published in the following Dove Press journal: \\ Vascular Health and Risk Management \\ 26 March 2014 \\ Number of times this article has been viewed
}

\author{
Bennett Levitan' \\ Zhong Yuan' \\ Alexander GG Turpie ${ }^{2}$ \\ Richard J Friedman ${ }^{3}$ \\ Martin Homering ${ }^{4}$ \\ Jesse A Berlin' \\ Scott D Berkowitz ${ }^{5}$ \\ Rachel B Weinstein' \\ Peter M DiBattiste ${ }^{6}$ \\ 'Janssen Research \& Development, \\ LLC, Titusville, NJ, USA; ${ }^{2}$ Hamilton \\ Health Sciences McMaster Clinic, \\ McMaster University, Hamilton, ON, \\ Canada; ${ }^{3}$ Charleston Orthopaedic \\ Associates, Charleston, SC, USA; \\ ${ }^{4}$ Bayer HealthCare, Berlin, Germany; \\ ${ }^{5}$ Bayer HealthCare Pharmaceuticals, \\ Whippany, NJ, USA; ${ }^{6}$ Janssen Research \\ \& Development, Raritan, NJ, USA
}

Purpose: Venous thromboembolism is a common complication after major orthopedic surgery. When prescribing anticoagulant prophylaxis, clinicians weigh the benefits of thromboprophylaxis against bleeding risk and other adverse events. Previous benefit-risk analyses of the REgulation of Coagulation in ORthopaedic surgery to prevent Deep vein thrombosis and pulmonary embolism (RECORD) randomized clinical studies of rivaroxaban versus enoxaparin after total hip (THA) or knee (TKA) arthroplasty generally used pooled THA and TKA results, counted fatal bleeding as both an efficacy and a safety event, and included the active and placebo-controlled portions of RECORD2, which might confound benefit-risk assessments. We conducted a post hoc analysis without these constraints to assess benefit-risk for rivaroxaban versus enoxaparin in the RECORD studies.

Patients and methods: Data from the safety population of the two THA and two TKA studies were pooled separately. The primary analysis compared the temporal course of event rates and rate differences between rivaroxaban and enoxaparin prophylaxis for symptomatic venous thromboembolism plus all-cause mortality (efficacy events) versus nonfatal major bleeding (safety events). Additionally, these rates were used to derive measures of net clinical benefit, number needed to treat (NNT), and number needed to harm (NNH) for these two end points.

Results: After THA or TKA, and compared with enoxaparin, rivaroxaban therapy resulted in more efficacy events prevented than safety events caused, with benefits exceeding harms early and throughout treatment and follow-up. Relative to enoxaparin, rivaroxaban treatment prevented six efficacy events per harm event caused for THA, with NNT $=262 / \mathrm{NNH}=1,711$. For TKA, rivaroxaban treatment prevented four to five efficacy events per harm event caused, with $\mathrm{NNT}=102 / \mathrm{NNH}=442$. Sensitivity analysis that included surgical-site bleeding resulted in $\mathrm{NNH}=345$ for THA and $\mathrm{NNH}=208$ for TKA.

Conclusion: In the RECORD studies, considering death, symptomatic venous thromboembolism, and major bleeding, rivaroxaban resulted in greater benefits than harms compared with enoxaparin. When incorporating surgical-site bleeding, rivaroxaban also results in greater benefit than harm for TKA and is balanced with enoxaparin for THA.

Keywords: VTE, DVT, PE, thromboprophylaxis, total hip arthroplasty, total knee arthroplasty

\section{Introduction}

Venous thromboembolism (VTE), comprising deep vein thrombosis (DVT) and pulmonary embolism (PE), is common after total hip arthroplasty (THA) and total knee arthroplasty (TKA) without thromboprophylaxis. During the 90 days after primary arthroplasty, in patients who receive thromboprophylaxis, hospitalization resulting from symptomatic 
DVT occurs in $0.7 \%$ of THA patients and $0.9 \%$ of TKA patients, and hospitalization resulting from PE occurs in $0.3 \%$ of patients in both groups. ${ }^{1}$ VTE is associated with significant morbidity and mortality; ${ }^{2}$ DVT may lead to recurrent VTE or post-thrombotic syndrome, ${ }^{2-4}$ and nonfatal $\mathrm{PE}$ may result in chronic thromboembolic pulmonary hypertension. ${ }^{5,6}$

Despite the availability of thromboprophylactic therapies, the prevention of VTE after THA or TKA remains a challenge, in part owing to increased risk of bleeding and the drawbacks of existing chemothromboprophylaxis. ${ }^{1,7-9}$ Warfarin is a common and important therapeutic option, although it usually takes several days to achieve pharmacologic effect and requires regular coagulation monitoring to ensure that the target international normalized ratio is achieved and maintained. ${ }^{10}$ Low-molecularweight heparins (eg, enoxaparin) do not require the same level of careful monitoring but must be administered parenterally. Rivaroxaban is an oral anticoagulant that directly inhibits Factor Xa and does not require routine coagulation monitoring. The REgulation of Coagulation in ORthopaedic surgery to prevent Deep vein thrombosis and pulmonary embolism (RECORD) Phase III clinical trial program compared the efficacy and safety of rivaroxaban with enoxaparin for the prevention of VTE after elective THA and TKA. ${ }^{1-14}$ Rivaroxaban demonstrated superiority to various enoxaparin regimens in the reduction of postoperative total VTE (composite of any DVT, nonfatal PE, and all-cause mortality) in the individual RECORD trials and pooled analyses; ${ }^{11-15}$ however, there were nonstatistically significant increases in major bleeding alone and in the composite of major and nonmajor clinically relevant bleeding in the individual studies, and there was a statistically significant increase in the composite of major and nonmajor clinically relevant bleeding in the pooled safety population.
For thromboprophylaxis, clinicians weigh the benefits of reduced rates of DVT and PE against the increased rate of bleeding. Approaches to assess drug benefit-risk have been considered by both industry and regulatory groups, ${ }^{16-21}$ but there are few regulatory guidelines for conducting benefit-risk analyses. Generally, efficacy and safety results are reported separately, and the benefit-risk balance tends to be characterized qualitatively, as in previous analyses of the RECORD studies. ${ }^{15,22,23}$ The number of quantitative assessments of benefit-risk profiles of anticoagulants is growing, however. ${ }^{24-32}$ The purpose of this paper is to quantitatively assess benefit versus risk for rivaroxaban versus enoxaparin in the RECORD studies, in patients who had THA or TKA.

\section{Patients and methods RECORD studies}

Between February 7, 2006 and January 31, 2008, 12,729 patients were randomized in the RECORD program. ${ }^{11-15}$ Men and women aged 18 years or older scheduled to undergo THA or TKA were eligible. Of the randomized patients, 12,383 were included in the safety analysis. ${ }^{15}$ The same number of patients in both groups $(n=173)$ were excluded from the safety population because they did not receive any study medication. ${ }^{15}$ The primary reasons for study discontinuation were similar between the groups and included consent withdrawn, clinical end point reached, noncompliance, protocol violation, adverse events (AEs), and other reason. ${ }^{15}$ The two groups were well balanced in terms of demographic and surgical characteristics. ${ }^{15}$

The four studies were of similar design but had important differences (Figure 1). In RECORD1 and RECORD2 (THA), patients received rivaroxaban until day $35 \pm 4$, with enoxaparin

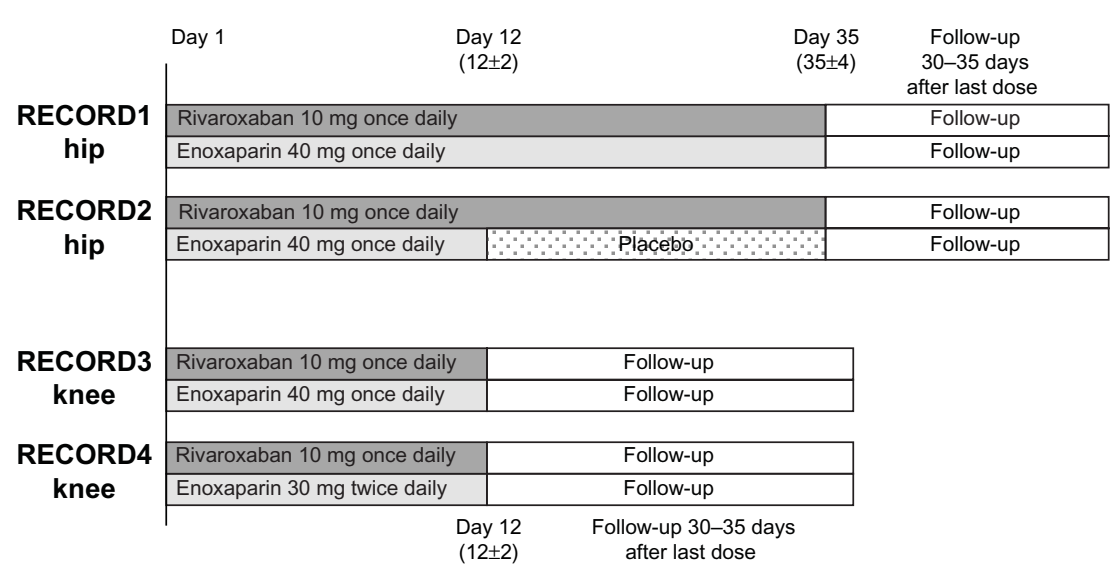

Figure I RECORD study designs.

Notes: Treatment regimens and duration of treatment and follow-up in the RECORDI" and RECORD2'2 studies were conducted in patients undergoing total hip arthroplasty, and in the RECORD3 ${ }^{13}$ and RECORD4 ${ }^{14}$ studies, they were conducted in patients undergoing total knee arthroplasty. Day I denotes the day of surgery. Abbreviation: RECORD, REgulation of Coagulation in ORthopaedic surgery to prevent Deep vein thrombosis and pulmonary embolism. 
given until day $35 \pm 4$ in RECORD1 and until day $12 \pm 2$ followed by placebo in RECORD2. In RECORD3 and RECORD4 (TKA), prophylaxis with rivaroxaban or enoxaparin was given until day $12 \pm 2$. Ten milligrams of rivaroxaban (initiated 6-8 hours postoperatively once hemostasis was assured) was administered orally once daily in all four studies. Subcutaneous enoxaparin was dosed at $40 \mathrm{mg}$ once daily beginning preoperatively in RECORD1, RECORD2, and RECORD3, and at $30 \mathrm{mg}$ twice daily beginning postoperatively in RECORD4. Patients underwent mandatory bilateral venography the day after the last dose of study drug. In all four studies, patients were followed for 30-35 days after treatment.

\section{End points and rates analyzed}

Symptomatic VTE, all-cause mortality, bleeding, wound infection, and reoperation-related end points were among the end points analyzed (Table 1). Composite end points were analyzed using time-to-first event analysis. End points were assessed in the safety population, which included all patients who had taken at least one dose of study medication and all events from first dose to the end of follow-up. Details on data collection in the RECORD studies are described in previously published papers. ${ }^{11-15}$

Previous benefit-risk analyses of the RECORD studies used pooled data from all four studies to enable more precise estimates of the incidence of uncommon but clinically important events. ${ }^{28,33}$ Here, the data from the two THA studies and the two TKA studies are pooled separately to enable assessment of the different time course of benefit-risk after both types of arthroplasty. Earlier pooled analyses of the RECORD studies also generally utilized relative effect measures (odds ratio or hazard ratio)..$^{15}$ Our analyses use rate differences between rivaroxaban and active enoxaparin treatment to show more clearly the number of events caused versus those prevented. Finally, to allow for a head-to-head comparison, only the treatment-controlled portion of RECORD2 is included. Therefore, follow-up time is truncated so that events in both arms of RECORD2 are censored (omitted) starting 2 days after the last administration of enoxaparin in the enoxaparin arm or matching treatment in the rivaroxaban arm (treatment duration $12 \pm 2$ days). All events from first dose to end of the planned follow-up period (active study duration) in the other three studies are included. For RECORD1, this includes events up to day 70 (35 days active treatment + 35 days follow-up). For the TKA studies, this includes events up to day 47 (12 days treatment +35 days follow-up).

\section{Benefit-risk assessment}

The primary analysis compares the temporal course of event rates and rate differences for symptomatic VTE plus

Table I Efficacy and safety end points analyzed

\begin{tabular}{|c|c|}
\hline End point & Description \\
\hline $\begin{array}{l}\text { Symptomatic venous thromboembolism } \\
\text { and all-cause mortality }\end{array}$ & $\begin{array}{l}\text { Symptomatic deep vein thrombosis, nonfatal pulmonary embolism, and death as a result of } \\
\text { any cause. }\end{array}$ \\
\hline Symptomatic venous thromboembolism & Fatal or nonfatal symptomatic deep vein thrombosis and nonfatal pulmonary embolism. \\
\hline All-cause mortality & Death as a result of any cause. \\
\hline Major bleeding ${ }^{\mathrm{a}}$ & $\begin{array}{l}\text { Bleeding, fatal or nonfatal, into a critical organ (eg, intracranial, retroperitoneal, intraocular, } \\
\text { intraspinal), that required reoperation, that was clinically overt in an extrasurgical site } \\
\text { associated with a } \geq 2 \mathrm{~g} / \mathrm{dL} \text { fall in hemoglobin, or that was clinically overt in an extrasurgical } \\
\text { site associated with transfusion of } \geq 2 \text { units of whole blood or packed cells. }{ }^{I-14}\end{array}$ \\
\hline Nonfatal major bleeding & Major bleeding excluding fatal bleeding events. \\
\hline Nonfatal major bleeding leading to reoperation & Major bleeding that required reoperation, excluding fatal bleeding events. \\
\hline Nonmajor clinically relevant bleeding ${ }^{\mathrm{a}}$ & $\begin{array}{l}\text { Overt bleeding not meeting the criteria for major bleeding and including events such as } \\
\text { hematoma }>25 \mathrm{~cm}^{2} \text {, spontaneous nosebleed }>5 \text { minutes, macroscopic hematuria, and } \\
\text { hematemesis (full definition in Turpie et al). } .^{14}\end{array}$ \\
\hline Nonfatal major plus surgical-site bleeding & $\begin{array}{l}\text { Major bleeding with inclusion of clinically overt surgical-site bleeding events associated } \\
\text { with } \geq 2 \mathrm{~g} / \mathrm{dL} \text { fall in hemoglobin or infusion of } \geq 2 \text { units of whole blood or packed cells. }\end{array}$ \\
\hline Surgical wound infections & $\begin{array}{l}\text { Investigator-reported incision-site infection, postprocedural infection, postoperative } \\
\text { wound infection, wound infection, wound infection bacterial, wound infection } \\
\text { staphylococcal, wound infection viral, wound infection fungal, wound sepsis, wound } \\
\text { abscess, incision-site abscess, or postoperative abscess. }\end{array}$ \\
\hline $\begin{array}{l}\text { Surgical wound infections leading to } \\
\text { rehospitalization/prolongation of hospitalization }\end{array}$ & $\begin{array}{l}\text { As above (Surgical wound infections information) with investigator assessment that the } \\
\text { event led to rehospitalization or prolongation of hospitalization. }\end{array}$ \\
\hline All investigator-reported serious adverse events & $\begin{array}{l}\text { Events that resulted in death; were life-threatening; required, or prolonged hospitalization; } \\
\text { resulted in persistent or significant disability; or were otherwise important medically. }\end{array}$ \\
\hline
\end{tabular}

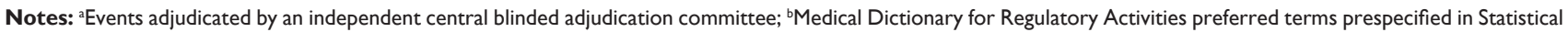
Analysis Plan for the pooled REgulation of Coagulation in ORthopaedic surgery to prevent Deep vein thrombosis and pulmonary embolism (RECORD) I-4 analysis. ${ }^{15}$ 
all-cause mortality versus nonfatal major bleeding. This efficacy end point was chosen to capture symptomatic events from the primary efficacy end point of the individual trials. The comparison with the risk of major bleeding was used because it was the most severe type of bleeding measured. Because fatal bleeding events are already included in allcause mortality, the comparison uses nonfatal major bleeding to avoid counting the same event twice.

In addition to comparing Kaplan-Meier rates of symptomatic VTE plus all-cause mortality versus nonfatal major bleeding, this analysis compared number needed to treat (NNT) and number needed to harm (NNH) for these two end points and assessed a measure of net clinical benefit. NNT and NNH were defined as the number of individuals who need to be exposed, on average, to one treatment versus the other to prevent one harmful efficacy event or to induce one additional harmful safety event, respectively. NNT and NNH were calculated as the reciprocal of the respective Kaplan-Meier rate differences. Net clinical benefit was defined as the sum of the rate differences for symptomatic VTE plus all-cause mortality and nonfatal major bleeding, and it can be interpreted as the difference between the numbers of safety events caused and efficacy events prevented by rivaroxaban compared with enoxaparin in a hypothetical cohort of 10,000 patients. Negative net clinical benefit indicates fewer harmful events associated with rivaroxaban than with enoxaparin treatment.

\section{Comparison of clinical severity for efficacy and safety end points}

The comparison should ideally be made using end points with similar clinical impact. Across the four RECORD studies, for symptomatic VTE and major bleeding events (Table 2), the same percentages of both types of event were classified by investigators as severe (27\%) or requiring hospitalization (54\%), where severe was defined as preventing normal activities; however, symptomatic venous thromboembolic events were more likely than bleeding events to be considered serious by investigators ( $99 \%$ versus $70 \%$ ) or to require remedial therapy ( $86 \%$ versus $30 \%$ ). Symptomatic VTE also had a longer median duration than major bleeding events: 29 days for symptomatic VTE in both THA and TKA patients compared with 6.5 days for major bleeding in THA patients and 2 days in TKA patients, leading to a greater probability of a case of symptomatic VTE being unresolved at discharge from hospital. Finally, the median time to onset of symptomatic VTE (18 days for THA; 5 days for TKA) was longer than that for major bleeding ( 1 day for THA; 3 days for TKA), leading to greater chance of a case of symptomatic VTE occurring after hospital discharge.

In all measures used, investigators regarded symptomatic VTE as having a clinical impact similar to or greater than that of major bleeding, and, by extension, similar to or greater than that of nonfatal major bleeding as used in the analyses below. Additionally, only one major bleeding event in the RECORD studies was a hemorrhagic stroke. ${ }^{33}$ Although these observations suggest that symptomatic VTE plus all-cause mortality events had greater clinical impact than the nonfatal major bleeding events in RECORD,,$^{24,30}$ to be conservative in our assessment, we regarded the two end points as having equal clinical impact.

\section{Results}

After THA, rivaroxaban prevented more harmful efficacy events than enoxaparin but was associated with more safety

Table 2 Clinical impact comparisons of symptomatic venous thromboembolic events versus major bleeding events pooled over both treatment arms from REgulation of Coagulation in ORthopaedic surgery to prevent Deep vein thrombosis and pulmonary embolism (RECORD) I-4 over the treatment period ${ }^{15}$

\begin{tabular}{llll}
\hline Parameter & $\begin{array}{l}\text { Symptomatic venous } \\
\text { thromboembolism (n=97) }\end{array}$ & $\begin{array}{l}\text { Major bleeding } \\
(\mathbf{n = 3 7})\end{array}$ & $\begin{array}{l}\text { Nonmajor clinically } \\
\text { relevant bleeding (n=349) }\end{array}$ \\
\hline Severe intensity (\%) & 27 & 27 & 8 \\
Serious event (\%) & 99 & 70 & 22 \\
Hospitalization or prolongation of hospitalization (\%) & 54 & 54 & 14 \\
Outcome unresolved (\%) & 46 & 14 & 10 \\
Action - remedial therapy (\%) & 86 & 30 & 25 \\
Duration of event, median (days) & & & 3.0 \\
$\quad$ Hip & 29.0 & 6.5 & 5.0 \\
$\quad$ Knee & 29.0 & 2.0 & 3.0 \\
Onset time from surgery, median (days) & 18.0 & & 3.0 \\
$\quad$ Hip & 5.0 & 3.0 & \\
$\quad$ Knee & & 3.0 & \\
\hline
\end{tabular}

Notes: All parameters shown were identified by investigators in the adverse event section of case report forms. Temporal measures show results for hip and knee arthroplasty separately. All other measures show results pooled over all four RECORD studies. aPatients with missing or insufficient data were excluded. 
events (Figure 2A). The number of efficacy events that were prevented was greater than the number of harms caused, both early and throughout treatment and follow-up, with rates plateauing at a ratio of six efficacy events prevented per harm caused (Figure 2B). In 10,000 patients, compared with enoxaparin, rivaroxaban would be expected to be associated with 38 (95\% confidence interval [CI]: -6 to 82) fewer symptomatic VTE plus all-cause mortality events and six (95\% CI: -15 to 26$)$ more nonfatal major bleeding events (Table 3 ). These data correspond to NNT $=262$ and $\mathrm{NNH}=1,711$; for every 262 patients receiving rivaroxaban versus enoxaparin, one fewer symptomatic VTE or death would be expected to occur. In contrast, 1,711 patients would need to be treated to see one more nonfatal major bleeding event. Assuming these efficacy and safety events have equal clinical impact, summing the rate differences gives a net
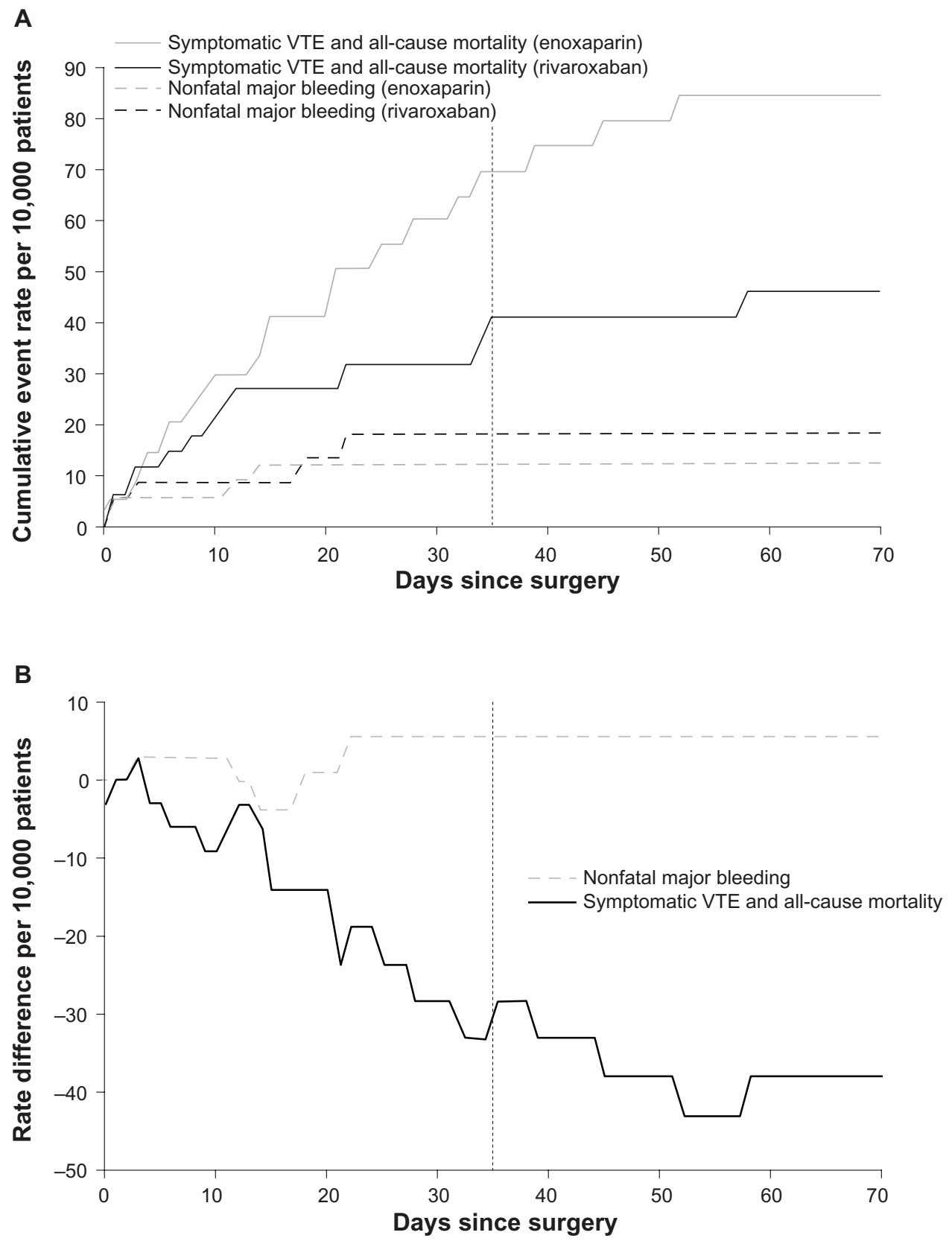

Figure 2 Temporal course of net clinical benefit is shown for VTE prophylaxis after total hip arthroplasty.

Notes: (A) Kaplan-Meier curves for symptomatic VTE plus all-cause mortality versus nonfatal major bleeding. The rate is shown per 10,000 patients. (B) Kaplan-Meier rate differences per 10,000 patients. Negative values favor rivaroxaban; positive values favor enoxaparin. The dashed vertical line indicates the end of treatment. The sum of the two lines is net clinical benefit. Data shown are RECORDI" and RECORD2'2 pooled with patients censored from RECORD2 from 2 days after the active-controlled phase. Abbreviations: RECORD, REgulation of Coagulation in ORthopaedic surgery to prevent Deep vein thrombosis and pulmonary embolism; VTE, venous thromboembolism. 
Table 3 Kaplan-Meier event rates, rate difference, number needed to treat/number needed to harm, and net clinical benefit for total hip arthroplasty (RECORDI and RECORD2) and total knee arthroplasty (RECORD3 and RECORD4) patients

\begin{tabular}{|c|c|c|c|c|c|c|c|}
\hline \multirow[t]{2}{*}{ End point } & \multicolumn{2}{|c|}{ Events per 10,000 patients } & \multicolumn{2}{|c|}{$\begin{array}{l}\text { Rate difference } \\
\text { (per } 10,000 \text { patients) } \\
\text { (rivaroxaban - enoxaparin) }\end{array}$} & \multirow[t]{2}{*}{$\begin{array}{l}\text { NNT or } \\
\text { NNH }\end{array}$} & \multicolumn{2}{|c|}{$\begin{array}{l}\text { Net clinical benefit } \\
\text { (sum of rate } \\
\text { differences) }\end{array}$} \\
\hline & Rivaroxaban & Enoxaparin & n & $95 \% \mathrm{Cl}$ & & $\mathbf{n}$ & $95 \% \mathrm{Cl}$ \\
\hline \multicolumn{8}{|c|}{ RECORDI" and RECORD2'12 (day 70) - total hip arthroplasty } \\
\hline $\begin{array}{l}\text { Symptomatic VTE plus } \\
\text { all-cause mortality }\end{array}$ & 46 & 84 & -38 & -82 to 6 & 262 & -32 & $-8 \mid$ to 16 \\
\hline Nonfatal major bleeding & 18 & 12 & 6 & -15 to 26 & $\mathrm{I}, 7 \mathrm{II}$ & & \\
\hline \multicolumn{8}{|c|}{ RECORD $^{13}$ and RECORD4 ${ }^{14}$ day 47$)$ - total knee arthroplasty } \\
\hline $\begin{array}{l}\text { Symptomatic VTE plus } \\
\text { all-cause mortality }\end{array}$ & $|2|$ & 219 & -98 & -169 to -27 & 102 & -76 & -157 to 6 \\
\hline Nonfatal major bleeding & 71 & 48 & 23 & -19 to 64 & 442 & & \\
\hline
\end{tabular}

Notes: Rates, rate differences, and net clinical benefit are per 10,000 patients, eg, the rate difference of six nonfatal major bleeding events per 10,000 patients corresponds to an additional $0.06 \%$ nonfatal major bleeding events on rivaroxaban. For total hip arthroplasty, patients in both arms of RECORD2 were censored from 2 days after the active control treatment phase. The net clinical benefit is not always the numeric sum of the rate differences shown owing to rounding in the values displayed. $95 \% \mathrm{Cls}$ provide a measure of uncertainty but are not intended for statistical hypothesis testing.

Abbreviations: $\mathrm{Cl}$, confidence interval; NNH, number needed to harm; NNT, number needed to treat; RECORD, REgulation of Coagulation in ORthopaedic surgery to prevent Deep vein thrombosis and pulmonary embolism; VTE, venous thromboembolism.

clinical benefit of 32 fewer symptomatic VTE, all-cause mortality, or nonfatal major bleeding events with rivaroxaban compared with enoxaparin per 10,000 patients. If this analysis were repeated using nonfatal major plus surgical-site bleeding instead of nonfatal major bleeding (a valuable sensitivity analysis, because the RECORD studies did not include surgical-site bleeding under their definition of major bleeding), the net clinical benefit would be nine ( $95 \%$ CI: -67 to 85 ) fewer events associated with rivaroxaban, and an $\mathrm{NNH}$ of 345 , or 1.3 efficacy events prevented per harm event caused. Of the rate difference for symptomatic VTE plus all-cause mortality, $20 \%-25 \%$ was attributed to reductions in death, and most of the rate difference for nonfatal major bleeding resulted from major bleeding events leading to reoperation (Table 4). Major plus nonmajor clinically relevant bleeding favored enoxaparin (primarily owing to nonmajor clinically relevant bleeding). The combination of nonfatal major bleeding and surgical-site bleeding also favored enoxaparin. Comparison with nonfatal major bleeding demonstrated that most of these events were surgical-site nonmajor bleeding events. Surgical wound infections and those leading to rehospitalization or prolongation of hospitalization, which includes many of the bleeding events listed, favored enoxaparin. The end point of any serious AE, which included all efficacy and safety events in the RECORD studies, favored rivaroxaban.

After TKA, rivaroxaban prevented more harmful efficacy events than enoxaparin but was associated with more safety events (Figure 3A). The number of efficacy events that were prevented was greater than the number of harm events caused. This began early in treatment and continued throughout treatment and follow-up, with rates plateauing at four to five efficacy events prevented per harm caused (Figure 3B). In 10,000 patients, compared with enoxaparin, rivaroxaban was associated with 98 (95\% CI: 27 to 169) fewer symptomatic VTE plus all-cause mortality events and 23 (95\% CI: -19 to 64) more nonfatal major bleeding events. These data correspond to NNT $=102$ and NNH $=442$. Net clinical benefit was 76 fewer symptomatic VTE, all-cause mortality, or nonfatal major bleeding events for rivaroxaban versus enoxaparin per 10,000 patients. Sensitivity analysis using nonfatal major plus surgical-site bleeding instead of nonfatal major bleeding yielded a net clinical benefit of 50 (95\% CI: -48 to 148 ) fewer events associated with rivaroxaban, and an NNH of 208, or two efficacy events prevented per harm event caused. The 98 fewer efficacy events per 10,000 patients associated with rivaroxaban treatment exceeded the increase in risk for any bleeding event assessed (Table 4). Approximately $20 \%$ of these efficacy events were attributable to death. Most of the rate difference for nonfatal major bleeding was attributable to bleeding events leading to reoperation. Surgical wound infections and those leading to rehospitalization or prolongation of hospitalization favored rivaroxaban, as did all serious AEs.

\section{Discussion}

Clinicians make benefit-risk decisions regarding thromboprophylaxis after THA and TKA by weighing the benefit of a reduction in venous thromboembolic events against the increased risk of bleeding. Previous benefit-risk analyses of the RECORD studies generally used pooled THA and TKA results, counted fatal bleeding as both an efficacy and a safety event, and included the placebo-controlled portion of RECORD2. ${ }^{28,31,33,34}$ We conducted a post hoc 
Table 4 Kaplan-Meier event rates and rate difference per 10,000 patients after total hip arthroplasty and total knee arthroplasty over treatment and follow-up period

\begin{tabular}{|c|c|c|c|}
\hline \multirow[t]{2}{*}{ End point } & \multicolumn{2}{|c|}{ Events per 10,000 patients } & \multirow{2}{*}{$\begin{array}{l}\text { Rate difference } \\
\text { (per } 10,000 \text { patients) } \\
\text { (rivaroxaban - enoxaparin) }\end{array}$} \\
\hline & Rivaroxaban & Enoxaparin & \\
\hline \multicolumn{4}{|c|}{ RECORDI" and RECORD2 ${ }^{12}$ (day 70) - total hip arthroplasty } \\
\hline Symptomatic VTE plus all-cause mortality & 46 & 84 & $-38(-82$ to 6$)$ \\
\hline Symptomatic VTE & 30 & 65 & $-36(-74$ to 2$)$ \\
\hline All-cause mortality & 17 & 25 & $-8(-33$ to 16$)$ \\
\hline Major bleeding & 21 & 12 & $9(-12$ to 30$)$ \\
\hline Nonfatal major bleeding & 18 & 12 & $6(-15$ to 26$)$ \\
\hline Nonfatal major bleeding leading to reoperation & 8 & 3 & $5(-8$ to 17$)$ \\
\hline Nonmajor clinically relevant bleeding & 334 & 264 & $70(-16$ to 155$)$ \\
\hline Nonfatal major plus surgical-site bleeding & 186 & 157 & $29(-34$ to 91$)$ \\
\hline Major plus nonmajor clinically relevant bleeding & 352 & 277 & $76(-12$ to 163$)$ \\
\hline Surgical wound infections & 175 & 153 & $22(-46$ to 91$)$ \\
\hline $\begin{array}{l}\text { Surgical wound infections leading to } \\
\text { rehospitalization/prolongation of hospitalization }\end{array}$ & 75 & 52 & $24(-20$ to 67$)$ \\
\hline Serious adverse events & 827 & 978 & $-150(-304$ to 4$)$ \\
\hline \multicolumn{4}{|c|}{ RECORD $^{13}$ and RECORD4 $4^{14}$ (day 47) - total knee arthroplasty } \\
\hline Symptomatic VTE plus all-cause mortality & $12 \mid$ & 219 & $-98(-169$ to -27$)$ \\
\hline Symptomatic VTE & 102 & 178 & $-75(-140$ to $-1 \mathrm{I})$ \\
\hline All-cause mortality & 23 & 42 & $-19(-50$ to 12$)$ \\
\hline Major bleeding & 75 & 48 & $26(-16$ to 68$)$ \\
\hline Nonfatal major bleeding & 71 & 48 & $23(-19$ to 64$)$ \\
\hline Nonfatal major bleeding leading to reoperation & 49 & 30 & $19(-15$ to 52$)$ \\
\hline Nonmajor clinically relevant bleeding & 278 & 242 & $37(-48$ to 122$)$ \\
\hline Nonfatal major plus surgical-site bleeding & 189 & $|4|$ & $48(-20$ to 116$)$ \\
\hline Major plus nonmajor clinically relevant bleeding & 342 & 290 & $52(-42$ to 145$)$ \\
\hline Surgical wound infections & 159 & 181 & $-22(-92$ to 48$)$ \\
\hline $\begin{array}{l}\text { Surgical wound infections leading to } \\
\text { rehospitalization/prolongation of hospitalization }\end{array}$ & 34 & 49 & $-15(-50$ to 20$)$ \\
\hline Serious adverse events & 832 & $\mathrm{I}, 038$ & $-206(-367$ to -45$)$ \\
\hline
\end{tabular}

Note: For total hip arthroplasty, patients in both arms of RECORD2 were censored from 2 days after the active control treatment phase.

Abbreviations: $\mathrm{Cl}$, confidence interval; RECORD, RECORD, REgulation of Coagulation in ORthopaedic surgery to prevent Deep vein thrombosis and pulmonary embolism; VTE, venous thromboembolism.

analysis without these constraints to quantitatively assess benefit-risk in the RECORD studies.

In the THA RECORD studies, the reduction in symptomatic VTE plus all-cause mortality exceeded the increase in nonfatal (and essentially non-stroke) ${ }^{33}$ major bleeding. The net benefit was observed early and maintained throughout treatment and follow-up. Net benefit was also obtained when balancing the efficacy end point against nonfatal major plus surgical-site bleeding, of particular importance for postoperative management. The analytic approach was designed specifically for benefit-risk assessment and avoids the constraints in prior benefit-risk analyses for RECORD listed above. In particular, censoring the placebo-controlled portions of RECORD2 avoids potentially overestimating the treatment benefit of rivaroxaban.

In the TKA studies of the RECORD program, the reduction in symptomatic VTE plus all-cause mortality also exceeded the increase in nonfatal (non-stroke) major bleeding. As with the THA studies, the net benefit was observed early, was maintained throughout treatment and follow-up, and was also obtained when balancing the efficacy end point against nonfatal major plus surgical-site bleeding. The absolute risk difference of symptomatic VTE plus all-cause mortality and that for nonfatal major bleeding were larger for TKA compared with those for THA patients (Table 3). Similar findings were obtained in the Global Orthopaedic Registry, which showed higher rates of DVT and bleeding complications after TKA. ${ }^{35}$ Despite these differences, the relative magnitude of benefit of rivaroxaban, in terms of events prevented per harmful event caused, was similar across the indications: in THA patients, approximately six symptomatic VTE plus all-cause mortality events were prevented per nonfatal major bleeding event caused; in TKA patients, the ratio was approximately four to five events prevented per nonfatal major bleeding event caused. 

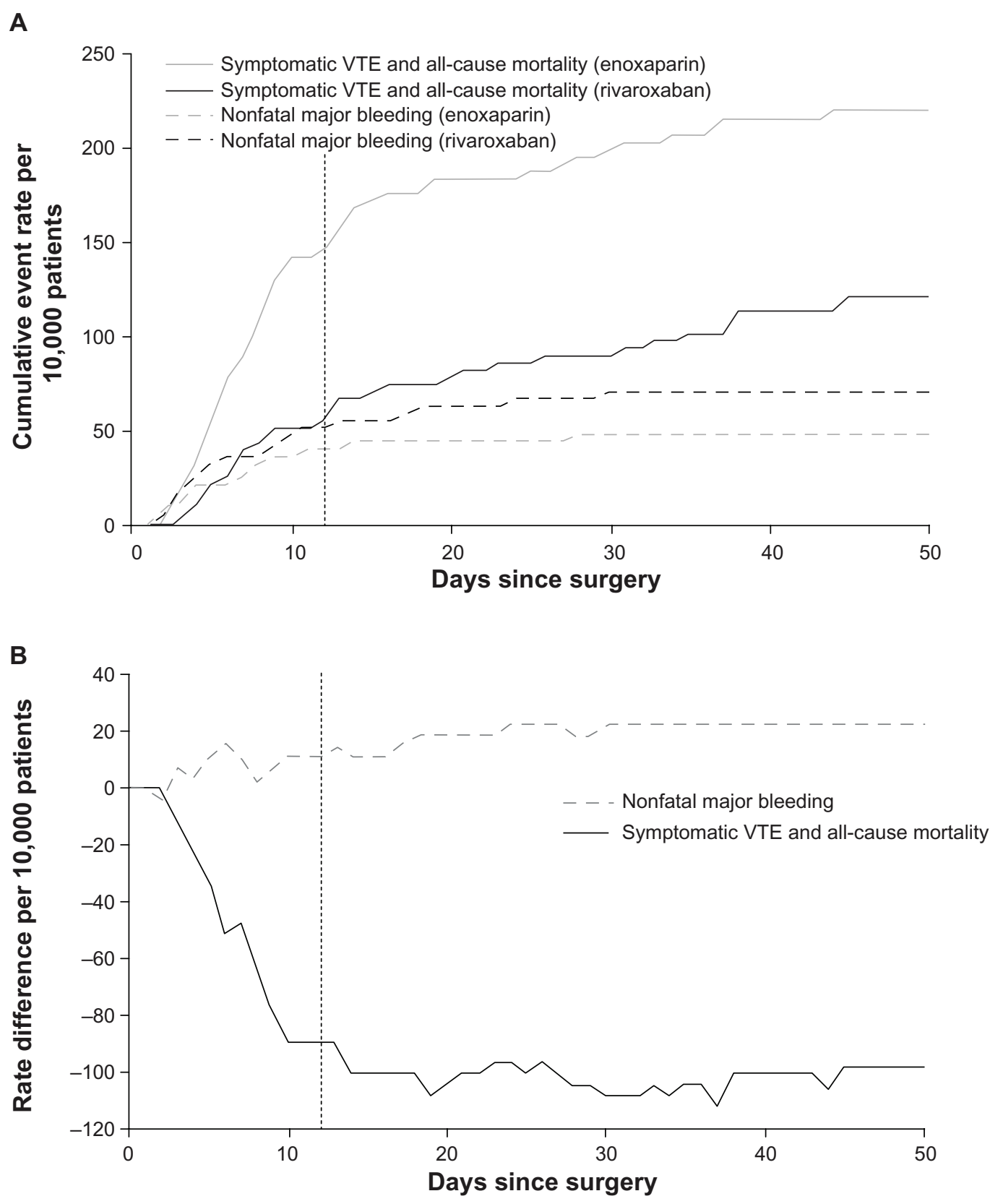

Figure 3 Temporal course of net clinical benefit is shown for VTE prophylaxis after total knee arthroplasty.

Notes: (A) Kaplan-Meier curves for symptomatic VTE plus all-cause mortality versus nonfatal major bleeding. The rate is shown per I0,000 patients. (B) Kaplan-Meier rate differences per 10,000 patients. Negative values favor rivaroxaban; positive values favor enoxaparin. The dashed vertical line indicates the end of treatment. The sum of the two lines is net clinical benefit. Data shown are RECORD3 ${ }^{13}$ and RECORD4 ${ }^{14}$ pooled.

Abbreviations: RECORD, REgulation of Coagulation in ORthopaedic surgery to prevent Deep vein thrombosis and pulmonary embolism; VTE, venous thromboembolism.

The sensitivity analysis in which nonfatal major plus surgical-site bleeding was used instead of nonfatal major bleeding showed less net clinical benefit for rivaroxaban compared with enoxaparin for TKA and, essentially, a benefit-risk balance between rivaroxaban and enoxaparin for THA. These results are similar to those reported by Gómez-Outes et al in $2012,{ }^{32}$ though our analysis defines net clinical benefit as the sum of rate differences for symptomatic VTE plus all-cause mortality and the rate difference for nonfatal major bleeding, whereas the analysis by Gómez-Outes et al defined net clinical benefit as the composite end point of symptomatic VTE, all-cause death, and major bleeding. The results for THA may be due in part to the 2 weeks' data used in RECORD2 due to censoring the placebo-controlled portion of that study.

A few limitations of the present analysis are noteworthy. First, using Kaplan-Meier rates in these post hoc analyses required choosing a time point for reporting rates. Theoretically, selection of the time point could show 
treatment in an especially favorable or unfavorable light; however, the plateaus for rate difference in Figures $2 \mathrm{~B}$ and $3 \mathrm{~B}$ show that the choice of dates did not influence the results. Second, the RECORD studies were not designed to track long-term consequences of wound infection (beyond 70 days for THA and 47 days for TKA) nor whether such infections led to reoperation. ${ }^{36,37}$ Hence, the data do not support measurements of the rates of reoperation or implant replacement owing to wound infection or similar measures. Related end points, the between-treatment differences for surgical wound infections overall and those leading to rehospitalization or prolongation of hospitalization, were small but numerically favored enoxaparin for THA (decrease of $0.22 \%$ and $0.24 \%$, respectively) and numerically favored rivaroxaban for TKA (decrease of $0.22 \%$ and $0.15 \%$, respectively). The $95 \%$ CIs for the hip and knee rate differences of these end points overlap considerably; these end points were not centrally adjudicated; and no biologic mechanism that would account for this difference by site (hip versus knee) was apparent. Although a recent analysis supports an assessment of no treatment difference for various complications of surgery after THR or TKR, ${ }^{34}$ additional studies would clearly be helpful for this topic. A third limitation is that the analysis did not account for patients potentially halting thromboprophylaxis owing to the impact of bleeding, an important issue but one that is outside the scope of the trial data. Finally, the analyses gave the same weight to nonfatal major bleeding as to symptomatic VTE plus all-cause mortality. However, as described, investigator reports from the RECORD trials suggested that symptomatic venous thromboembolic events in RECORD were, on average, of greater clinical impact than the major bleeding events observed, and hence also of greater clinical impact than nonfatal major bleeding. ${ }^{33}$ The relative clinical impact of bleeding and VTE is a complex topic with multiple perspectives. ${ }^{29,33,38,39}$ Even if nonfatal major bleeding was regarded as a more severe event on average than symptomatic VTE plus all-cause mortality, a typical nonfatal, non-stroke major bleed would have to be regarded as more than four to five times as severe as symptomatic VTE plus all-cause mortality for the benefit-risk assessment to switch to favoring enoxaparin.

An additional "limitation" of this work is more a consequence of the heterogeneity of the end points used in thromboprophylaxis studies. Symptomatic VTE ranges from DVTs that cause discomfort and swelling to fatal PEs. Major bleeding ranges from transient drops in hemoglobin that require only supportive care through hemorrhagic stroke, fatal bleeding, and intracranial hemorrhage. Considering such a wide range of events as having a similar clinical impact is clearly a rough approximation at best; however, decomposing these end points into separate measurements with a narrower range of impact can result in very low event rates with high uncertainty. An alternative approach is to use a set of weights for each end point that reflect their rough clinical impact, then multiply the rate differences by these weights in the net clinical benefit calculation. The weights would then be varied over a realistic range to provide a sensitivity analysis to the results, an approach used by Singer et al in 2009. ${ }^{29}$ In our analysis, we assumed equal weighting for symptomatic VTE plus all-cause mortality and for nonfatal major bleeding. Given that the measurements in Table 2 all suggest that the clinical impact of nonfatal major bleeding is less than that of symptomatic VTE plus all-cause mortality, we regard the current analysis as on the conservative side that would favor enoxaparin, though this is clearly a topic for further research.

The results in this work align with those from prior benefit-risk assessments for the RECORD studies ${ }^{28,32-34}$ and address some of the topics raised by other authors; ${ }^{31}$ however, because these prior assessments pooled all four of the RECORD studies, whereas the current work censored the placebo comparator portion of RECORD2, some 95\% CIs for risk differences here are larger than in prior reports. Of interest, in this and the prior analyses, clinicians generally prefer NNT values considerably smaller than the 100-300 observed here; however, these numbers reflect the comparison of a study drug with a highly effective comparator, that is, in the setting of low baseline rates. ${ }^{28,32-34}$ Thus, the NNT should be interpreted in the context of clinical practice where the alternative is not placebo but other effective treatments. We note, however, that the $\mathrm{NNH}$ (to cause an additional bleeding event) is four- to six-fold larger than the NNT. ${ }^{9,15}$

Clinical practice decisions depend on many factors beyond formal benefit-risk assessments, such as the oral once-daily formulation of rivaroxaban, the absence of need for regular international normalized ratio monitoring with rivaroxaban, and the lack of availability of any antidote for rivaroxaban. This analysis suggests that rivaroxaban is a viable option compared with enoxaparin for thromboprophylaxis after THA or TKA.

\section{Acknowledgment}

We thank Li Wan, a medical writer, who provided editorial support during preparation of this manuscript. Funding for editorial support was provided by Bayer HealthCare Pharmaceuticals and Janssen Scientific Affairs, LLC. 


\section{Disclosure}

BL, ZY, JAB, RBW, and PMD are employees of Janssen Research \& Development, LLC; BL and RBW are invested in a portfolio that periodically includes health care and biotechnology companies; $\mathrm{MH}$ is an employee of Bayer HealthCare; and $\mathrm{SDB}$ is an employee of Bayer HealthCare Pharmaceuticals. AGGT has received consultancy fees from Bayer HealthCare, Janssen Pharmaceutical Research \& Development, Astellas, Portola, and Takeda. RJF has received consultancy fees from Janssen, J\&J, Exactech, DJO Surgical, and Cadence. The authors report no other conflicts of interest in this work.

\section{References}

1. Preventing Venous Thromboembolic Disease in Patients Undergoing Elective Hip and Knee Arthroplasty: Evidence-Based Guideline and Evidence Report. Rosemont, IL: American Academy of Orthopaedic Surgeons; 2011. Available from: http://www.aaos.org/research/ guidelines/VTE/VTE_full_guideline.pdf. Accessed October 1, 2013.

2. Kearon C. Natural history of venous thromboembolism. Circulation. 2003;107(23 Suppl 1):I22-I30.

3. Kahn SR, Hirsch A, Shrier I. Effect of postthrombotic syndrome on health-related quality of life after deep venous thrombosis. Arch Intern Med. 2002;162(10):1144-1148.

4. Kahn SR, Ginsberg JS. Relationship between deep venous thrombosis and the postthrombotic syndrome. Arch Intern Med. 2004;164(1): $17-26$.

5. Lang I, Kerr K. Risk factors for chronic thromboembolic pulmonary hypertension. Proc Am Thorac Soc. 2006;3(7):568-570.

6. Pengo V, Lensing AWA, Prins MH, et al. Thromboembolic Pulmonary Hypertension Study Group. Incidence of chronic thromboembolic pulmonary hypertension after pulmonary embolism. $N$ Engl $J$ Med. 2004;350(22):2257-2264.

7. Eikelboom JW, Karthikeyan G, Fagel N, Hirsh J. American Association of Orthopedic Surgeons and American College of Chest Physicians guidelines for venous thromboembolism prevention in hip and knee arthroplasty differ: what are the implications for clinicians and patients? Chest. 2009; 135(2):513-520.

8. Falck-Ytter Y, Francis CW, Johanson NA, et al. American College of Chest Physicians. Prevention of VTE in orthopedic surgery patients: Antithrombotic Therapy and Prevention of Thrombosis, 9th ed: American College of Chest Physicians Evidence-Based Clinical Practice Guidelines. Chest. 2012;141(Suppl 2):e278S-e325S.

9. Warwick D, Friedman RJ, Agnelli G, et al. Insufficient duration of venous thromboembolism prophylaxis after total hip or knee replacement when compared with the time course of thromboembolic events: findings from the Global Orthopaedic Registry. J Bone Joint Surg Br. 2007;89(6):799-807.

10. Ageno W, Gallus AS, Wittkowsky A, Crowther M, Hylek EM, Palareti G. American College of Chest Physicians. Oral anticoagulant therapy: Antithrombotic Therapy and Prevention of Thrombosis. 9th ed: American College of Chest Physicians Evidence-Based Clinical Practice Guidelines. Chest. 2012;141(Supp1 2):e44S-e88S.

11. Eriksson BI, Borris LC, Friedman RJ, et al; RECORD1 Study Group. Rivaroxaban versus enoxaparin for thromboprophylaxis after hip arthroplasty. N Engl J Med. 2008;358(26):2765-2775.

12. Kakkar AK, Brenner B, Dahl OE, et al; RECORD2 Investigators. Extended duration rivaroxaban versus short-term enoxaparin for the prevention of venous thromboembolism after total hip arthroplasty: a double-blind, randomised controlled trial. Lancet. 2008;372(9632):31-39.
13. Lassen MR, Ageno W, Borris LC, et al; RECORD3 Investigators. Rivaroxaban versus enoxaparin for thromboprophylaxis after total knee arthroplasty. N Engl J Med. 2008;358(26):2776-2786.

14. Turpie AGG, Lassen MR, Davidson BL, et al; RECORD4 Investigators. Rivaroxaban versus enoxaparin for thromboprophylaxis after total knee arthroplasty (RECORD4): a randomised trial. Lancet. 2009;373(9676): $1673-1680$

15. Turpie AGG, Lassen MR, Eriksson BI, et al. Rivaroxaban for the prevention of venous thromboembolism after hip or knee arthroplasty. Pooled analysis of four studies. Thromb Haemost. 2011;105(3):444- 453.

16. Coplan PM, Noel RA, Levitan BS, Ferguson J, Mussen F. Development of a framework for enhancing the transparency, reproducibility and communication of the benefit-risk balance of medicines. Clin Pharmacol Ther. 2011;89(2):312-315.

17. Benefit-risk methodology [webpage on the Internet]. London: European Medicines Agency; 2011. Available from: http://www.ema. europa.eu/ema/index.jsp?curl=pages/special_topics/document_listing/ document_listing_000314.jsp\&mid=WC0b01ac0580223ed6\&murl= menus/special_topics/special_topics.jsp\&jsenabled=true. Accessed July 16, 2013.

18. Levitan BS, Andrews EB, Gilsenan A, et al. Application of the BRAT framework to case studies: observations and insights. Clin Pharmacol Ther. 2011;89(2):217-224.

19. Structured Approach to Benefit-Risk Assessment in drug Regulatory Decision-Making. US Food and Drug Administration; 2013. Available from: http://www.fda.gov/downloads/ForIndustry/UserFees/ PrescriptionDrugUserFee/UCM329758.pdf. Accessed September 2, 2013.

20. Benefit-risk integration and representation [webpage on the Internet]. PROTECT Investigators Innovative Medicines Initiative. Available from: http://www.imi-protect.eu/benefitPres.shtml. Accessed July 16, 2013.

21. Walker S, Liberti L, McAuslane N, Levitan BS. Refining the benefit-risk framework for the assessment of medicines: valuing and weighting benefit and risk parameters. Clin Pharmacol Ther. 2011;89(2):179-182.

22. Bauer KA, Turpie AGG, Lassen MR, Kakkar AK, Eriksson BI, Gent M; RECORD 1-4 Investigators. Effects of age, weight, gender and renal function in a pooled analysis of four rivaroxaban studies. $J$ Thromb Haemost. 2009;7(S2):767:PP-WE-421.

23. Eriksson BI, Kakkar AK, Turpie AGG, et al. Oral rivaroxaban for the prevention of symptomatic venous thromboembolism after elective hip and knee replacement. J Bone Joint Surg Br. 2009;91(5):636-644.

24. Beasley BN, Unger EF, Temple R. Anticoagulant options - why the FDA approved a higher but not a lower dose of dabigatran. $N$ Engl $J$ Med. 2011;364(19):1788-1790.

25. Gibson CM, Levitan B, Murphy SA, et al. A net clinical outcome analysis comparing fatal or irreversible ischemic and bleeding events in ATLAS ACS 2 - TIMI 51. Circulation. 2012;126:A13152.

26. Hull RD, Yusen RD, Bergqvist D. State-of-the-art review: assessing the safety profiles of new anticoagulants for major orthopedic surgery thromboprophylaxis. Clin Appl Thromb Hemost. 2009;15(4):377-388.

27. Kaul S, Diamond GA. Does rivaroxaban provide a clinically relevant favorable benefit-risk profile compared with enoxaparin after hip or knee arthroplasty? J Am Coll Cardiol. 2010;55(10):E1616-E1618: A172.

28. Levitan B, Yuan Z, Turpie AGG, et al. Quantitative benefitrisk assessment of rivaroxaban for the prevention of venous thromboembolism. Blood (ASH Annual Meeting Abstracts). 2009;114(22):75-76:A169.

29. Singer DE, Chang Y, Fang MC, et al. The net clinical benefit of warfarin anticoagulation in atrial fibrillation. Ann Intern Med. 2009;151(5): 297-305.

30. Unger EF. Weighing benefits and risks - the FDA's review of prasugrel. N Engl J Med. 2009;361(10):942-945. 
31. Van Thiel D, Kalodiki E, Wahi R, Litinas E, Haque W, Rao G. Interpretation of benefit-risk of enoxaparin as comparator in the RECORD program: rivaroxaban oral tablets (10 milligrams) for use in prophylaxis in deep vein thrombosis and pulmonary embolism in patients undergoing hip or knee replacement surgery. Clin Appl Thromb Hemost. 2009;15(4):389-394.

32. Gómez-Outes A, Terleira-Fernández AI, Suárez-Gea ML, VargasCastrillón E. Dabigatran, rivaroxaban, or apixaban versus enoxaparin for thromboprophylaxis after total hip or knee replacement: systematic review, meta-analysis, and indirect treatment comparisons. BMJ. 2012;344:e3675

33. Advisory Committee Briefing Book: Rivaroxaban for the Prophylaxis of Deep Vein Thrombosis (DVT) and Pulmonary Embolism (PE) in Patients Undergoing Hip or Knee Replacement Surgery. Johnson \& Johnson Pharmaceutical Research and Development, LLC; 2009. Available from: http://www.fda.gov/downloads/AdvisoryCommittees/ CommitteesMeetingMaterials/Drugs/CardiovascularandRenalDrugsAd visoryCommittee/UCM138385.pdf. Accessed September 2, 2013

34. Lassen MR, Gent M, Kakkar AK, et al. The effects of rivaroxaban on the complications of surgery after total hip or knee replacement: results from the RECORD programme. J Bone Joint Surg Br. 2012;94(11): 1573-1578.
35. Cushner F, Agnelli G, FitzGerald G, Warwick D. Complications and functional outcomes after total hip arthroplasty and total knee arthroplasty: results from the Global Orthopaedic Registry (GLORY). Am J Orthop (Belle Mead NJ). 2010;39(Suppl 9):22-28.

36. Jameson SS, Rymaszewska M, James P, et al. Wound complications following rivaroxaban administration: a multicenter comparison with low-molecular-weight heparins for thromboprophylaxis in lower limb arthroplasty. J Bone Joint Surg Am. 2012;94(17):1554-1558.

37. Jensen CD, Steval A, Partington PF, Reed MR, Muller SD. Return to theatre following total hip and knee replacement, before and after the introduction of rivaroxaban: a retrospective cohort study. J Bone Joint Surg Br. 2011;93(1):91-95.

38. Chan CM, Zilberberg MD. Preferences in traumatic intracranial hemorrhage: bleeding vs. clotting. Crit Care. 2010;14(3):153.

39. Lip GYH, Piotrponikowski P, Andreotti F, et al. Thromboembolism and antithrombotic therapy for heart failure in sinus rhythm. An Executive Summary of a joint Consensus Document from the ESC Heart Failure Association and the ESC Working Group on Thrombosis. Thromb Haemost. 2012;108(6): 1009-1022.
Vascular Health and Risk Management

\section{Publish your work in this journal}

Vascular Health and Risk Management is an international, peerreviewed journal of therapeutics and risk management, focusing on concise rapid reporting of clinical studies on the processes involved in the maintenance of vascular health; the monitoring, prevention and treatment of vascular disease and its sequelae; and the involvement of

\section{Dovepress}

metabolic disorders, particularly diabetes. This journal is indexed on PubMed Central and MedLine. The manuscript management system is completely online and includes a very quick and fair peer-review system, which is all easy to use. Visit http://www.dovepress.com/ testimonials.php to read real quotes from published authors. 